\title{
Comparison between Endoscopic and Curettage Adenoidectomy
}

\section{Original Article}

\author{
Saad Abdulraheem Hussein \\ Department of Surgery, Babylon Medical College, Iraq.
}

\begin{abstract}
Introduction: Adenoidectomy is a procedure to remove the adenoid tissue in the post nasal space, commonly done using curettage (conventional method) which is blind surgery.

Aim: To show the differences between curettage and endoscopic adenoidectomy regarding long term results, safety, and accuracy.

Patients and Methods: From October 2017 to October 2019 eighty (80) patients (32 males and 48 females) underwent adenoidectomy. They were divided into two groups, each group of forty patients. Group A underwent adenoidectomy by conventional curettage while group B underwent endoscopic adenoidectomy trans nasally assisted by debrider.

The parameters studied are, Intra operative time, complete excision, trauma during surgery, vello- pharyngeal insufficiency, adenoid remnant and lastly symptoms relief.

Results: Surgery time in group A is from 10-35 minutes(mean time is 23 minutes)while in group B is from 21-91 minutes (mean time is 42 minutes). Adenoidectomy is nearly complete in group B while 8 patients in group A had remnant adenoid tissue (20\%). Group A has associated trauma in 6 patients $(15 \%)$. (including minor trauma to uvula or posterior pharyngeal wall) while in group B 10 cases (25\%) have septal mucosal injury for which 4 patients need anterior nasal packing. Vello pharyngeal insufficiency occurred in 4 cases in group A while 6 patients affected in group B. All are mild and resolved within days. Infection occurred in 2 patients in both groups. Retained swab had occurred in 2 patients in group A while nil in group B.

Conclusion: Adenoidectomy by assisted endoscopy is accurate and safe because it fulfills complete excision of adenoid under direct visualization.
\end{abstract}

Key Words: Adenoidectomy, assisted endoscopy, curettage, nasopharynx.

Received: 8 March 2021, Accepted: 2 August 2021

Corresponding Author: Saad Abdulraheem Hussein, MD, Department of Surgery, Babylon Medical College, Iraq, Tel.: +9647801355315, E-mail: Aljubory65@gmail.com

ISSN: 2090-0740, 2021

\section{PATIENTS AND METHODS:}

This study was done at Hilla teaching hospital-Iraq. it is prospective study design. The research is approved by the board of ethical terms in the department of surgeryBabylon medical college, Iraq. Consents were taken from all the patients participating in this research.

80 patients were selected between age of four and twenty require adenoidectomy for different indications.

Clinical examination of nasal patency, aural xamination, nasopharynx radiology with endoscopic examination using fiber optic endoscope.

Assessment of adenoid size is done according to Clemens Mc murray scale. ${ }^{[1,9]}$

Grad I: adenoid tissue filling one third of the vertical height of of Choana.
Grad II: up to two third

Grad III: from two third o nearly complete obstruction of the Choana

Grad IV: complete Choanal obstruction

All cases were divided into two groups of forty patients, patients underwent adenoidectomy by curettage is labeled as group A. patients underwent endoscopic adenoidectomy assisted by shaver were labeled as group B.

All the surgical procedures were done under general anesthesia through oral intubation.

Curettage done using St. Clair Thompson curettage, while endoscope diameter $4 \mathrm{~mm}$ are commonly used in group B transnasaly assisted by microdebrider. In cases of difficult access I use one nasal cavity for endoscope while the other nasal cavity is used for shaver. no posterior packing or cautery is used during procedures. 
I studied intra operative time of surgery, bleeding, trauma and complete excision of adenoid tissue.

Post-operative adenoid remnant, incidence of infection, relief of symptoms and sleep disturbance were assessed

Data were analyzed into group A and B.

\section{Questionare:}

Name: $\quad$ age: sex:

phone number:

\section{Symptomes:}

Nasal obstruction mouth breathing: snoring

Nasal discharge sleep disturbance

otalgia

Deafness

\section{Assessment:}

Cotton test

Ear examination

Hearing assessment

Radiological examination

Nasal fiber optic examination

Mean time of surgery

\section{Complications:}

\section{Bleeding:}

- Primary
Trauma
Hyper nasality
Symptoms recondary

\section{RESULTS:}

Types of surgical procedure were classified into 3 procedures as shown by (Figure1) according to symptoms and clinical examination the majority underwent adenoidectomy alone followed by adenotonsillectomy as shown in (Table 1):

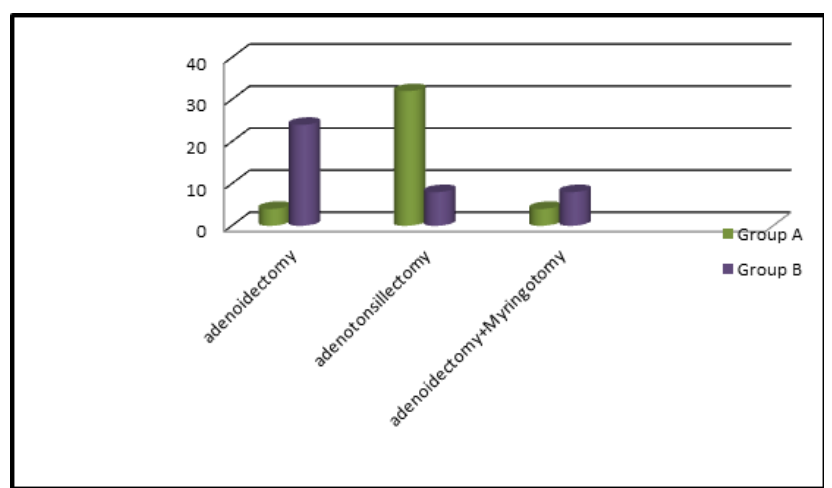

Table 1: Types of surgical procedure

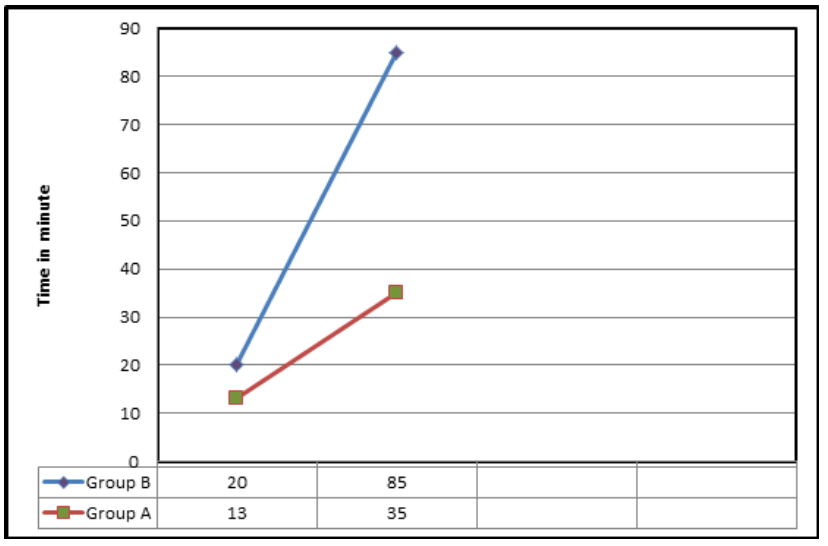

Table 2: Duration of surgical procedures

The indication for surgery Is mainly for snoring or sleep disturbances followed by adenotonsillitis as shown by (Table 3 )

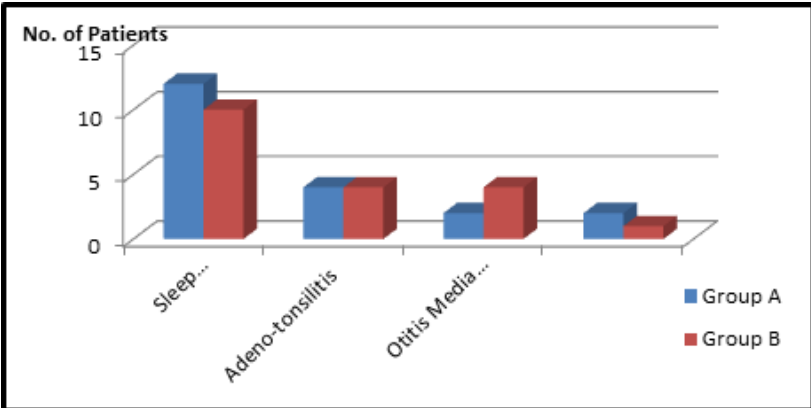

Table 3: Indications of surgery according to age

Post-operative fiber optic nose endoscopy was done for any remnant which was complete and satisfied in group B while 8 patient $20 \%$ remnant discovered in group A.

Trauma to adjacent structures were happened in 6 patients $15 \%$ in group A while in group B were 4 patients $10 \%$ which involved the septum and then treated by anterior nasal packing.

Vello pharyngeal incompetence occurred in 4 patients $10 \%$ in group A and in 6 patients $15 \%$ in group B, all of them were resolved spontaneously.

Infection happened in 2 patients in each group 5\%. 
Swab retained occurred in 2 patients $5 \%$ in group B only.

Over all symptoms were resolved in group B while 4 patients in group A were continue their symptoms (Table 4)

Table 4: Post-operative comparison between curettage and endoscopic adenoidectomy

\begin{tabular}{ccc}
\hline Parameter & $\begin{array}{c}\text { Curettage } \\
\text { adenoidectomy }\end{array}$ & $\begin{array}{c}\text { Adenoidectomy } \\
\text { by endoscope }\end{array}$ \\
\hline Time of operation & 23.25 minutes & 42.75 minutes \\
Remnant & $20 \%$ & None \\
Associated trauma & $15 \%$ & $25 \%$ \\
Velopharyngeal & $10 \%$ & $15 \%$ \\
Dysfunction & $5 \%$ & $5 \%$ \\
Infection & $5 \%$ & None \\
Retained swab & &
\end{tabular}

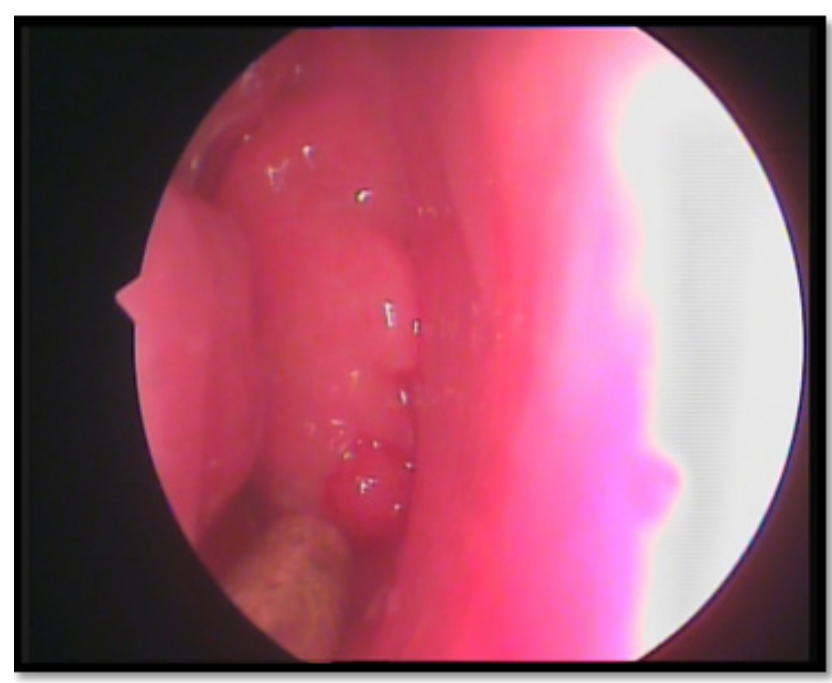

Fig. 1: Choanal adenoid

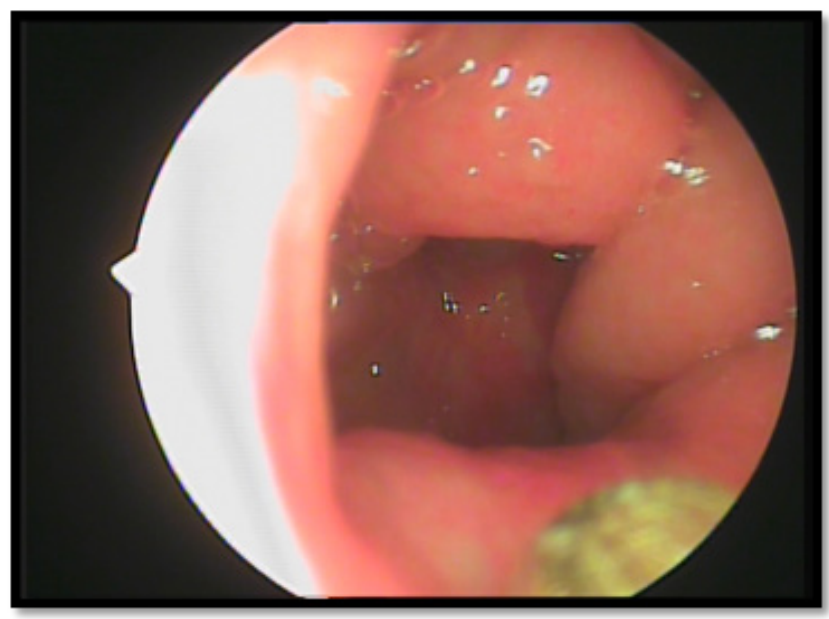

Fig. 2: post-operative view following conventional method

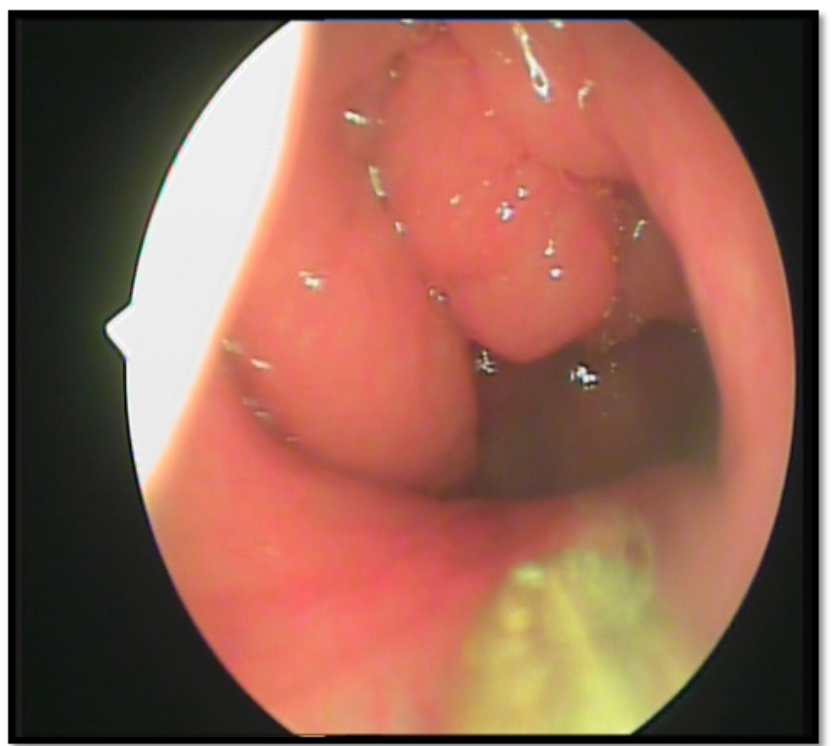

Fig. 3: post-operative view following conventional adenoidectomy (same patient on other side)

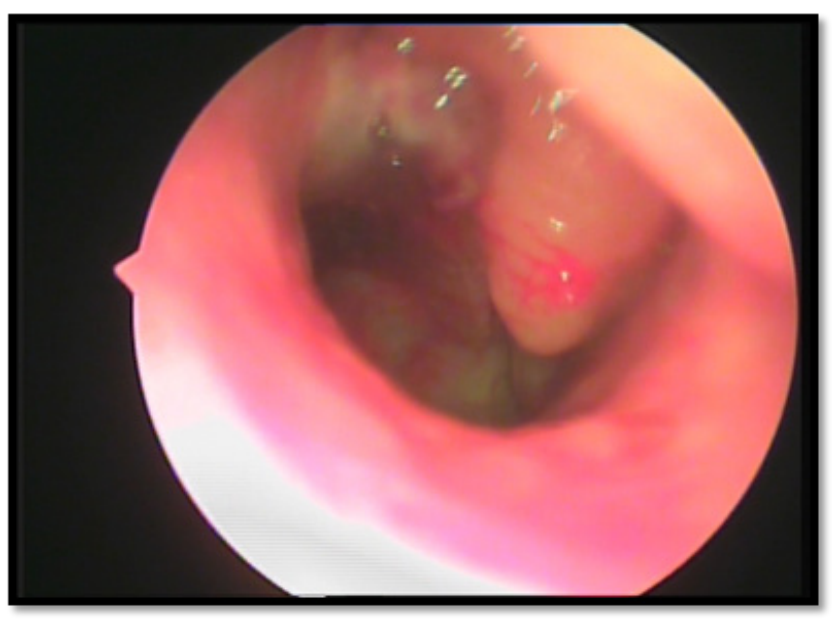

Fig. 4: post-operative view following endoscopic method.

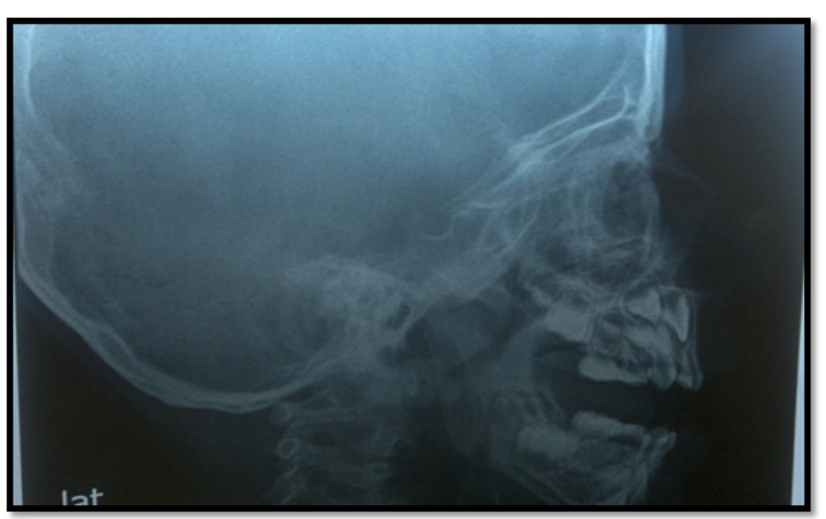

Fig. 5: -Lateral soft tissue view of nasopharynx (shows enlarged adenoid). 


\section{DISCUSSION}

Adenoidectomy using assisted endoscopy and debrider in comparison with curettage method which is commonly popular.

The access is better in group B while it is a blind procedure in group A and leads to incomplete removal with trauma to adjacent structures; therefore it leads to recurrence ${ }^{[4,5,6,7]}$.

In our results the mean time needed for surgery, in group B it is more than the time in group A due to preparation of nasal cavity, step by step surgery, hemostasis as well as surgeon experience.

This result is against the results of Stanislaw et al. ${ }^{[5]}$ and Feng Y. et al. ${ }^{[6]}$ They reported $20 \%$ faster in powered adenoidectomy than conventional way. They used angled debrider 45 degree through oro pharynx with laryngeal mirror aid.

Our results are consistent with results of Rakeh Datta $^{[4]}$ who concluded procedure safety, less bleeding, less damage but more time consuming in powered adenoidectomy.

Nasal obstruction is evident when adenoid tissue fill more than $40 \%$ of post nasal space. ${ }^{[1,13]}$

Rankeh Datta Stanislaw $\mathrm{P}$ and Koltai $\mathbf{P J}^{[4,5,7,]}$ reported that adenoidectomy can be excised accurately using endoscopy which is consistent with our study.

In this study adenoidectomy done in 10 adults patients by endoscopy which gives better access and less complications than in children.

Reda H. Kamel ${ }^{[8]}$ and Clemens J. ${ }^{[9]}$ reported that endoscopic method is effective with less bleeding, trauma but it takes longer time during surgery than the conventional method.

Elluru Ravindhra ${ }^{[10]}$, Gerhardsson $\mathrm{H}$, Stalfors J. ${ }^{[11]}$ and Mahmut Huntürk Atilla ${ }^{[12]}$ also denoted that endoscopic method has shorter operative time, less bleeding, more cost and needs experience in comparison with curettage method.

\section{CONCLUSION}

1- Endoscopic adenoidectomy is effective procedure in experienced hands in comparison with curettage method.

2- It is useful in special circumstances like adenoid extending to nasal cavity, sub mucosal cleft palate where they require partial adenoidectomy.

3-It is reliable in recurrent cases of adenoid hypertrophy.

\section{RECOMMENDATION}

1- Endoscopy is recommended for pre-operative assessment of adenoid size as well as surgical excision as it a reliable, accurate and safe method.

2- When the surgery done by conventional way, it is recommended to use endoscope for accurate excision and reduction of damage, recurrence and exclude retained swab in the nasal cavity or nasopharynx.

\section{ACKNOWLEDGMENTS}

Great Thanks and appreciation to all persons who assist and help in fulfillment of this research including resident doctors nurses and other workers in the department of Otolaryngology - Hilla Teaching Hospital

\section{CONFLICT OF INTEREST}

There are no conflicts of interest

\section{REFERENCES}

1. Peter J Robb. The adenoid and adenoidectomy. ScottBrown's otorhinolaryngology, Head and Neck surgery. Seventh edition, 2008;84:1094-98.

2. W. Peyton Shirley, Audie L. Wooly, Brian J. Wiatrak. Pharyngitis and adenotonsillar disease. Comming's otolaryngology, Head and neck surgery. fifth edition, 2010;196:2796-97.

3. Jhon E McClay, Arlen D Meyers. Adenoidectomy. Medscape reference. Sep 15, 2011; PP6.

4. Lt Col Rakesh Datta, Col VP Singh, Col Deshpal. Conventional versus endoscopic powered adenoidectomy: comparative study. Medical journal armed force of India. 2009; 65:308-312.

5. Stanislaw P, Koltia PJ, Feustel PJ. Comparison of powered - assisted adenoidectomy versus adenoid curette adenoidectomy. Archive of otolaryngologyHead and Neck surgery. 2000; 126:845-9.

6. Feng Y, Yin S. comparison of powered-assisted adenoidectomy with adenoid curette adenoidectomy. Chuang Er Bi Yan Hou Ke Za Zhi. 2006; 20:54-7.

7. Koltai PJ, Chan J, Youes A. powered-assisted adenoidectomy:total and partial resection. Laryngoscope. 2002;112:29-31.

8. Reda H. Kamel and Elia A. Ishat. An enlarged adenoid and adenoidectomy in adult:endoscopic approach and histopathological study. Journal of laryngology and otology. 29 june 2007; 7:965-67. 
9. Clemens J, McMurray JS, Willging JP. Electrocautery versus curette adenoidectomy:comparison of postoperative results. International journal of paediatrics otorhinolaryngology. 1998; 43:115-22.

10. Elluru RG, Johnson L, Meyer CM. Electrocautery adenoidectomy compared with curette and powered assisted method. Laryngoscope. 2002;112:23-5.
11. Gerhardsson H, Stalfors J, Odhagen E, Sunnergren O. Pediatric adenoid surgery in Sweden 2004-2013: incidence, indications and concomitant surgical procedures. Int $\mathrm{J}$ Paediatric Otorhinolaryngology. 2016;87:61-6

12. Mahmut HuntürkAtilla Comparison between curettage adenoidectomy and endoscopic-assisted microdebrider adenoidectomy Braz. j. otorhinolaryngol. vol.86 no.1 São Paulo Jan./Feb. 2020 Epub Mar 30, 2020 